\title{
Towards an understanding of neuropsychiatric manifestations in fragile $X$ premutation carriers
}

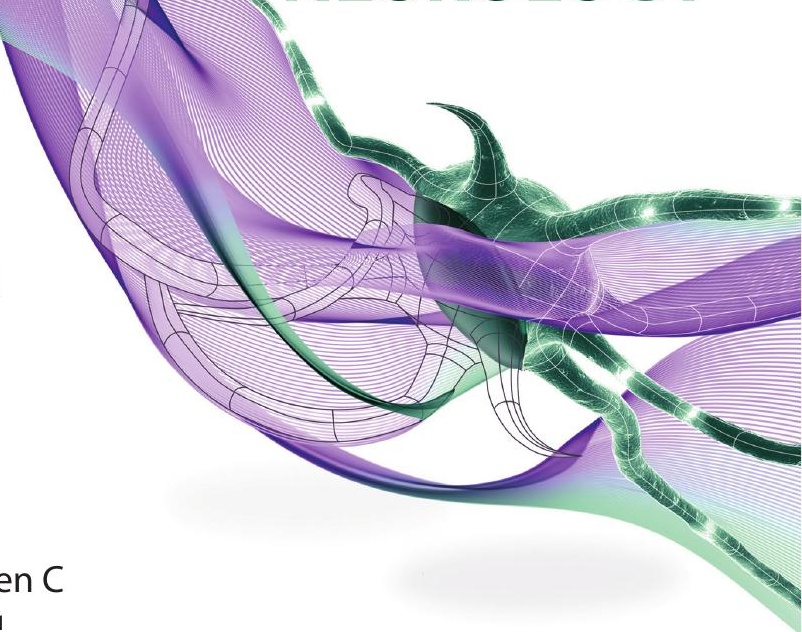

Aaron D Besterman ${ }^{\ddagger 1}$, Scott A Wilke ${ }^{\ddagger 1}$, Tua-Elisabeth Mulligan', Stephen C

Allison', Randi Hagerman², Andreea L Seritan² \& James A Bourgeois*1

\begin{abstract}
Fragile $X$-associated disorders are a group of disorders caused by expansion of noncoding CGG repeat elements in the fragile X (FMR1) gene. One of these disorders, fragile $X$ syndrome, is the most common heritable cause of intellectual disability, and is caused by large CGG repeat expansions (>200) resulting in silencing of the FMR1 gene. An increasingly recognized number of neuropsychiatric fragile $X$-associated disorders have recently been identified that are caused by 'premutation' range expansions (55-200). These disorders are characterized by a spectrum of neuropsychiatric manifestations ranging from an increased risk of neurodevelopmental, mood and anxiety disorders to neurodegenerative phenotypes, such as the fragile $\mathrm{X}$-associated tremor ataxia syndrome. This article reviews the advances in the clinical understanding of neuropsychiatric disorders in premutation carriers across the lifespan and offers guidance for the detection of such disorders by practicing psychiatrists and neurologists.
\end{abstract}

\section{Medscape Medscape: Continuing Medical Education Online}

This activity has been planned and implemented in accordance with the Essential Areas and policies of the Accreditation Council for Continuing Medical Education through the joint sponsorship of Medscape, LLC and Future Medicine Ltd. Medscape, LLC is accredited by the ACCME to provide continuing medical education for physicians.

Medscape, LLC designates this journal-based CME activity for a maximum of 1 AMA PRA Category 1 Credit(s) ${ }^{\mathrm{TM}}$. Physicians should claim only the credit commensurate with the extent of their participation in the activity.

All other clinicians completing this activity will be issued a certificate of participation. To participate in this journal CME activity: (1) review the learning objectives and author disclosures; (2) study the education content; (3) take the post-test with a $70 \%$ minimum passing score and complete the evaluation at www.medscape.org/journal/fnl; (4) view/print certificate.

RELEASE DATE: 3 MARCH 2014; EXPIRATION DATE: 3 MARCH 2015

'Department of Psychiatry, University of California, San Francisco School of Medicine, San Francisco, CA 94143, USA

2Department of Pediatrics \& MIND Institute, University of California, Davis School of Medicine, Sacramento, CA 95817, USA

${ }^{3}$ Department of Psychiatry \& Behavioral Sciences \& MIND Institute, University of California, Davis School of Medicine, Sacramento,

CA 95817, USA

*Author for correspondence: james.bourgeois@ucsf.edu

${ }^{\ddagger}$ Authors contributed equally

\section{KEYWORDS}

- ADHD • anxiety • ASD

- autism • depression $\bullet$ FMR1

- fragile $X$ premutation

- fragile $X$ syndrome - fragile

$X$-associated tremor ataxia syndrome • FXTAS 


\section{LEARNING OBJECTIVES}

Upon completion of this activity, participants should be able to:

- Describe neurodevelopmental fragile X premutation (FXPM) disorders in children who are fragile $X$ carriers, based on a review

- Identify neuropsychiatric phenotypes in adult carriers without fragile X-associated tremor ataxia syndrome (FXTAS) and their management

- Distinguish neuropsychiatric and other manifestations in patients with FXTAS

Financial \& competing interests disclosure

Editor: Elisa Manzotti, Publisher, Future Science Group.

Disclosure: Elisa Manzotti has disclosed no relevant financial relationships.

CME author: Laurie Barclay, MD, Freelance writer and reviewer, Medscape, LLC. Disclosure: Laurie Barclay, MD, has disclosed no relevant financial relationships.

Author \& credentials: Aaron D Besterman, MD, Department of Psychiatry, University of California, San Francisco School of Medicine, San Francisco, CA 94143, USA.

Disclosure: Aaron D Besterman has disclosed no relevant financial relationships.

Scott A Wilke, MD, PhD, Department of Psychiatry, University of California, San Francisco School of Medicine, San Francisco, CA 94143, USA.

Disclosure: Scott $A$ Wilke has disclosed no relevant financial relationships.

Tua-Elisabeth Mulligan, MD, Department of Psychiatry, University of California, San Francisco School of Medicine, San Francisco, CA 94143, USA.

Disclosure: Tua-Elisabeth Mulligan has disclosed no relevant financial relationships.

Stephen C Allison, MD, Department of Psychiatry, University of California, San Francisco School of Medicine, San Francisco, CA 94143, USA.

Disclosure: Stephen C Allison has disclosed no relevant financial relationships.

Randi Hagerman, MD, Department of Pediatrics \& MIND Institute, University of California, Davis School of Medicine, Sacramento, CA 95817, USA.

Disclosure: Randi Hagerman receives support from the National Institutes of Child Health and Human Development grant HD036071 and National Institutes of Mental Health grant MH078041-06. She has received support from Novartis, Roche, Seaside Therapeutics, Forest and Curemark for clinical trials in fragile X syndrome or autism. She also serves on the fragile $X$ advisory boards for Novartis and Roche.

Andreea L Seritan, MD, Department of Psychiatry \& Behavioral Sciences \& MIND Institute, University of California, Davis School of Medicine, Sacramento, CA 95817, USA.

Disclosure: Andreea L Seritan receives support from the National Institutes of Child Health and Human Development grant HD036071 and National Institutes of Mental Health grant MH078041-06.

James A Bourgeois, OD, MD, Department of Psychiatry, University of California, San Francisco School of Medicine, San Francisco, CA 94143, USA.

Disclosure: James A Bourgeois has disclosed no relevant financial relationships.

No writing assistance was utilized in the production of this manuscript.

Recent advances in clinical neurosciences have led to an increased recognition of illnesses that blur the historical distinctions between 'neurologic' and 'psychiatric'. The fragile X-associated disorders (FXD) represent a group of such neuropsychiatric illnesses, which include both fragile $\mathrm{X}$ syndrome (FXS) and fragile X premutation (FXPM) disorders. FXS is the most common cause of heritable intellectual disability and is also often associated with autism spectrum disorder (ASD), attention-deficit/hyperactivity disorder
(ADHD), learning difficulties and anxiety [1]. It is caused by an expansion of the CGG trinucleotide to $>200$ copies in the $5^{\prime}$ untranslated region of the FMR1 gene on the $\mathrm{X}$ chromosome (Xq27.3) [2]. Initially, it was believed that FXS was the only FXD and that anyone with the premutation (55-200 CGG repeats) was clinically unaffected. That is now known not to be the case. Individuals with the premutation, or 'carriers' as we will refer to them from now on, are susceptible to several FXD throughout the lifespan. 
Individuals with 45-54 CGG repeats in FMRI have a 'gray zone' allele, usually have mild elevations of FMR $1 \mathrm{mRNA}$ and may be susceptible to FXPM disorders, although to a lesser degree [3-6].

This review will focus primarily on carriers and the neuropsychiatric consequences of premutation status. The various neurodevelopmental phenotypes that commonly present in carriers, such as ASD, ADHD and seizures, are discussed. The burden of mood and anxiety disorders that affect many adult and some female child carriers is also discussed. These are sometimes accompanied by cognitive decline that may precede fragile X-associated tremor ataxia syndrome (FXTAS) and an associated cortical-subcortical dementia, the details of which continue to be fully elucidated. Some of the clinical neuroimaging findings in these disorders are highlighted to emphasize both the clinical and endophenotypic overlap with other neuropsychiatric disorders. Suggestions for appropriate genetic testing are provided, taking into consideration both psychiatric and neurological symptoms, with a strong emphasis on family history. Last, treatment suggestions for psychiatric symptoms based on reported clinical experience are provided, and the authors offer their thoughts on the most fruitful areas of future research to improve our understanding and treatment of FXPM disorders.

\section{Neurodevelopmental disorders in carriers}

An initial study comparing psychiatric phenotypes of carriers with related noncarriers found that there were few if any differences [7]. However, with further study, it became clear that some carriers presented with intellectual disability, learning disability or ASD [8-11]. There has since been significant investigation into the frequency of ASD in the carrier population. Many studies use a design that compares the phenotype of probands (carriers who are identified by presenting to clinicians for medical care) with related nonprobands (carriers who are identified secondary to genetic testing of family members of a proband). In an early case series, Aziz et al. described ten proband boys with high rates of social impairment, hyperactivity, delayed receptive and expressive vocabulary, and impaired social use of language [12]. The rate of ASD in carrier probands has since been found to be significantly higher than both nonprobands and related noncarriers $[10,11]$. Farzin et al. compared 14 male probands, 13 nonprobands and 16 related controls
[10]. They found that $79 \%$ of probands met the criteria for an ASD (29\% with autistic disorder and $50 \%$ with pervasive developmental disordernot otherwise specified). By contrast, only $8 \%$ of nonprobands met criteria for ASD. In a study of 50 boys ( 25 probands and 25 nonprobands) with the premutation, Chonchaiya et al. observed similar trends in the relative frequency of ASD [11]. Compared with noncarriers, ASD was significantly more frequent in both probands and nonprobands [11]. In studies of young adult male carriers social deficits consistent with ASD have also been observed [13]. Compared with unrelated noncarriers, carriers had poorer social cognition, with the most notable impairment on interpersonal skills that require accurate social perception, such as recognizing complex emotions from photographs of eyes [13].

Additional epidemiological data come from a national survey that asked parents to report neuropsychiatric symptoms, such as attention problems, hyperactivity, aggressiveness, self-injury, autism, seizures, anxiety or depression, along with the mutational status of all of their children [14]. They identified 211 female and 65 male carriers and compared them with sex-matched controls. In male carriers, $33 \%$ were reported to have developmental delay (DD), 41\% had attention problems, $19.3 \%$ had aggressiveness, $19.3 \%$ had autism, $11.3 \%$ had seizures and $33.3 \%$ had anxiety [14]. All conditions were significantly more common in carriers than in controls. By contrast, only $8.6 \%$ of females were reported to have DD, $1.1 \%$ had autism, $18.5 \%$ had attention problems, $35.6 \%$ had anxiety and $34.2 \%$ had depression, suggesting that mood disorders may be the most predominant psychiatric disorder in female children with the premutation [14]. The main limitation to this study was that all data were ascertained from parent reports, and were not verified for accuracy. In addition, there was a low response rate from low socioeconomic status and ethnic minority groups. Therefore, these results may not be broadly generalizable to all carriers. However, Clifford et al. observed similar trends in autism frequency in a study of seven male and 43 female carriers who ranged in age from 5 to 80 years, with $14.3 \%$ of males and $7 \%$ of females meeting the criteria for ASD [15]. Together, the data from these studies suggest that the relative frequency of ASD in carriers is approximately $10-20 \%$ in males and $1-7 \%$ in females. While frequency estimates of ASD in carriers varies somewhat between studies, likely 
owing to small sample sizes and variable study design, there is a consistent trend of elevated ASD rates in male carriers, and possibly female carriers, compared with the general population.

As seen in the national survey, there is some evidence that carriers, especially those with ASD, may also be at elevated risk for additional neurodevelopmental disorders, such as ADHD and seizure disorders [14]. In an early cohort study, daughters of carrier fathers, blinded to their father's carrier status, reported more frequent behaviors related to adult ADHD [16]. This was followed by several case studies reporting ADHD behaviors in child carriers, such as difficulty focusing and sitting still in class $[8,12,17]$ and a case-control study observing increased rates of ADHD in probands compared with nonprobands and noncarriers [10]. An additional study found a higher prevalence of adult ADHD in carriers compared to noncarriers [18]. The risk of developing a seizure disorder is similarly elevated in carriers. Chonchaiya et al. observed a significantly higher number of probands with a history of seizures $(28 \%)$ than nonprobands $(0 \%)$ or noncarrier control brothers $(0 \%)$, consistent with prior reports [11,14]. Probands with ASD were much more likely to have a seizure disorder, suggesting a potential etiologic overlap with idiopathic ASD, where seizures are also common [19].

\section{Neuropsychiatric phenotypes in adult carriers without FXTAS}

Adult carriers without FXTAS do not exhibit significant deficits in general intelligence compared with the general population [20]. However, aging carriers can experience significant executive function deficits and disinhibition [21-23]. Clinical reports have suggested that specific cognitive deficits may coincide with or precede the motor dysfunction of FXTAS in some cases [24,25]. While Hunter et al. did not initially find evidence of executive dysfunction in carriers younger than 50 years [26], several other studies have identified deficits in declarative and working memory, selective attention and response inhibition in similar groups without FXTAS $[20,22,27,28]$. Thus far, a limitation of such studies is that they do not track patients longitudinally in order to determine whether cognitive deficits predict development of FXTAS or represent a separate phenotype.

Initial investigations of the prevalence of neuropsychiatric disorders in carriers focused on mothers of children with FXS and found subtle differences or no differences at all compared with noncarriers [7,29]. However, subsequent studies have found elevated rates of mood and anxiety disorders in carriers. For example, in carrier mothers of children with FXS, Franke et al. reported a $55.7 \%$ lifetime incidence of mood disorders, of which $19.7 \%$ was major depression, and a $41 \%$ lifetime incidence of anxiety disorders [30]. Within the anxiety disorder classification, carriers may be at increased risk of developing social phobia, with recent estimates of lifetime prevalence of $34.2 \%$ in a population of both men and women carriers, compared with $12.6 \%$ in the general population, as measured in the National Comorbidity Survey Replication [31]. There is evidence that the elevated risk in this population may be secondary to a synergy between social stressors and the genetic risk itself. Franke et al. observed a frequency of social phobias of $18.0 \%$ in female carriers who have children with FXS, compared with $5.9 \%$ in intrafamilial female carriers without a child with FXS [30]. Both of these represent statistically significant elevations over the rate of noncarrier females with an autistic child of $0 \%$ that was used as the control. This study is limited by small sample size, as the $5.9 \%$ is a result of a single individual with social phobia and the prevalence of social phobia within the general population is $>0 \%$ (e.g., National Comorbidity Survey Replication data). However, it does suggest that the combination of the premutation with social stressors, such as raising a child with FXS, may put women at a significantly elevated risk of developing social phobia. An increased risk of other mood and anxiety disorders in carriers has also been observed. Roberts et al. conducted a study comparing 93 carrier females with 2159 gender- and age-matched controls from the National Comorbidity Survey Replication data set [32]. Using structured clinical interviews, they found an elevated lifetime risk of major depression (43.0 vs $31.9 \%$ ), panic disorder without agoraphobia (8.6 vs $2.3 \%$ ) and current agoraphobia without panic disorder (3.2 vs $0.7 \%$ ); however, interestingly, not social phobia. Other studies have similarly observed higher rates of depression, anxiety disorders, or both in carriers when compared to controls [33,34]. Taken as a whole, FXPM carriers appear to have a greater propensity to develop mood and anxiety disorders than the general population. Importantly, carriers have an average older age of onset for major depression, panic disorder and specific phobias compared with the general population [34]. 
There is very limited evidence on the frequency of personality or psychotic disorders in carriers. There has been reported elevations in schizoid and obsessive-compulsive spectrum personality features along with deficits in social cognition in carriers [13,35]. While individual cases of psychotic disorders have been noted in the literature $[36,37]$ and schizotypal features have been reported $[30,38]$, the rate of distinct psychotic disorders is not thought to be elevated compared with the general population $[30,39]$.

A number of studies have identified structural or functional deficits on MRI in adult carriers, which may underlie a vulnerability to developing neuropsychiatric phenotypes [40-46]. Reduced amygdala activation in carriers has been correlated with global psychological symptom severity [40]. Hessl et al. have reported that such blunted amygdala response is associated with deficits in social cognitive processing in adult carrier males $[40,41]$. Reduced hippocampal volume has been associated with anxiety symptoms in female carriers and reduced hippocampal activation during memory recall has been associated with higher psychiatric morbidity in male carriers $[42,43]$. Moreover, two recent studies have demonstrated reduced hippocampal and frontal cortex activation during memory tasks and reduced connectivity between these structures [44,45]. Finally, diffusion tensor imaging studies have demonstrated white matter deficits in carriers asymptomatic for FXTAS $[45,46]$. That such deficits exist in adults asymptomatic for FXTAS, particularly in limbic and frontal cortical areas, suggests a unique underlying neurobiological basis for increased susceptibility to neuropsychiatric phenotypes, including $\mathrm{ADHD}$, executive function deficits, disinhibition and impulsivity in carriers.

While disturbances in brain structure and function may predispose to the development of neuropsychiatric illness, several other factors are probably relevant. Some carriers may be more sensitive to psychosocial life stressors and case reports have suggested greater vulnerability when exposed to neurotoxic chemicals [47,48]. Higher rates of alcohol abuse have been documented in both male and female carriers, putting them at further risk for neuropsychiatric comorbidities [49,50]. The FXPM may also predispose individuals to non-CNS medical conditions, which may contribute to the development of neuropsychiatric disorders [50,51]. For example, before the age of 40 years, approximately $20 \%$ of female carriers develop fragile X premature ovarian insufficiency (POI), which is characterized by decreased ovarian function and can lead to infertility and early menopause [52]. The associated estrogen deficits and potential feelings of reproductive inadequacy put them at increased risk for mood disorders [53,54]. Similarly, carriers with and without FXTAS have substantial rates of thyroid dysfunction, a known risk factor for mood and anxiety disorders [51]. Carriers may also have an increased susceptibility to conditions such as migraine headaches, fibromyalgia, restless legs syndrome and sleep apnea [55-58]. On a stress-diathesis model of the development of neuropsychiatric disorders, all of these factors may combine with underlying brain abnormalities to produce an elevated risk for neuropsychiatric phenotypes in carriers.

\section{Neuropsychiatric phenotypes in FXTAS}

FXTAS is an often-debilitating movement disorder that occurs in some carriers and increases in prevalence with age. While rare before the age of 50 years, it affects $17 \%$ of male carriers in their 50s and $75 \%$ in their 80s [59] and up to $16 \%$ of female carriers [51,59-62]. Rarely, gray zone carriers may develop FXTAS as well [3]. FXTAS is characterized by progressive symptoms of tremor, ataxia and parkinsonism. Cognitive decline may occur in approximately $50 \%$ of men with FXTAS, at times progressing to dementia [25,34,63-65]. Female carriers become cognitively impaired less often, although there have been reports of women with FXTAS and dementia [66-69]. The predominant cognitive deficit is executive dysfunction, with only mildto-moderate decrements in memory, as assessed by the Folstein Mini-Mental State Examination [22]. Structured dimensional observations by caregivers using the NeuroPsychiatric Inventory noted marked agitation, disinhibition, irritability, apathy and depression, which were often out of proportion to the mild decrements measured on the Mini-Mental State Examination [70]. Interestingly, language and visuospatial skills, which are impaired early in Alzheimer's disease, remain relatively intact in FXTAS [22].

This pattern of deficits indicates that FXTAS dementia is a mixed cortical-subcortical dementia, similarly to corticobasal degeneration and dementia with Lewy bodies, which also have parkinsonism as a prominent feature [65,71]. Owing to the overlap of clinical signs and symptoms and the limited body of knowledge available to date, FXTAS dementia is difficult to distinguish from 
other dementias with movement disorders [71]. FXTAS may be mistaken for Parkinson's disease or spinocerebellar ataxia in some cases, although studies have identified the FMR 1 premutation in less than $1 \%$ of men clinically diagnosed with multiple system atrophy, Parkinson's disease or spinocerebellar ataxia [72-74].

A variety of affective and behavioral symptoms can also be seen in FXTAS [35]. Mood and anxiety disorders are common in FXTAS and occur at rates higher than in both age-adjusted controls and carriers without FXTAS [31]. There is a $52 \%$ lifetime prevalence of anxiety disorders in patients with FXTAS, including increased rates of panic disorder, specific phobias and PTSD, as well as a trend toward greater social anxiety compared with the general population prevalence [31]. Similarly, there is a 65\% lifetime prevalence of mood disorders in FXTAS, with major depressive disorder occurring twice as often as in age-adjusted norms [31]. Importantly, major depressive disorder has a considerably later onset in FXTAS (median age: 50 years) than is seen in the general population (median age: 32 years) and typically precedes the onset of tremor and ataxia [34]. A similar pattern appears to hold for anxiety disorders [34]. Suicidal thoughts occur in at least $5 \%$ of patients [39], which is particularly concerning given the frequent co-occurrence of impaired impulse control [31] and substance use disorders [39], which may further increase suicide risk. Suicide attempts in patients with FXTAS have also been reported [39]. The behavioral disturbances seen in FXTAS are likely related to brain changes in areas known to affect behavior. For example, gray matter atrophy has been observed in the dorsomedial prefrontal cortex, anterior cingulate cortex, orbitofrontal cortex, amygdala and insula $[40,44,75-77]$, areas implicated in behavioral disturbances in other dementia syndromes [78].

\section{Clinical indications for genetic testing in carriers}

Clinical pedigree analysis is important in placing premutation disorders in a proper context. The American Academy of Pediatrics currently recommends FMR1 DNA testing for all children with DD [79] and recommends testing as part of the etiologic workup of children with ASD [80] with or without DD. It follows that adults with undiagnosed DD or ASD should be tested for FMR1 mutations. Any evidence of FXS, or even intellectual disability or ASD, in a patient's family pedigree should also lead to greater clinical suspicion for a premutation disorder and trigger consideration of FMR1 DNA testing. Given the increased incidence of mood or anxiety disorders in carriers [31], adults with mood or anxiety disorders who have a family history of FXS, DD or ASD should also be screened [38].

Testing for the premutation should be offered to women suffering from POI, as the carrier status has been identified in approximately $1-8 \%$ of women with POI and up to approximately $13 \%$ of women with a family history of POI [81-83]. In the psychiatrist's office, women with both a mood or anxiety disorder and a history of POI or infertility should have FMR1 DNA testing. Critically, the development of one of these premutation disorders such as fragile $\mathrm{X}$ POI does not necessarily predispose a carrier to FXTAS [51]. FXTAS also clusters in families so that if a patient has relatives with FXTAS, this will increase the premutation carrier patient's risk for FXTAS with age, presumably because of background genetic factors associated with FXTAS, such as APO\&4 alleles [84].

Recently, two Spanish studies examined the incidence of the premutation in women with fibromyalgia. One study identified a nonsignificant trend towards increased frequency of the premutation, with one out of 88 women with fibromyalgia testing positive for the premutation compared with one out of 250 women without fibromyalgia, which is consistent with published frequency data for the average population ( 1/250-1/400) [57]. Another study observed a frequency that was similar to the estimated general population frequency (3/700 or $0.4 \%$ ) [85]. Further research into the incidence and differing clinical presentations of women with the premutation and fibromyalgia is indicated before recommending screening in this population, unless there are other symptoms such as tremor or a family history of FXD.

It has previously been recommended that adults with mood or anxiety disorders who have a family history of dementia, especially dementia with a movement disorder, should be tested for the premutation [25]. Carrier screening may be considered in adults presenting with cognitive impairment with or without a movement disorder [86], although screening of patients within the parkinsonism clinical spectrum without additional relevant history has not been found to be productive [72,73]. Finally, clinicians may encounter a patient being evaluated for cognitive 
impairment with or without movement disorders with an MRI finding of middle cerebellar peduncle T2 hyperintensity or 'MCP sign.' Given the high specificity of this finding, FMR1 DNA testing is indicated [87,88]. Patients with dementia on clinical examination who have a concurrent movement disorder, in particular, tremor and/or ataxia, should also be considered for FMR1 DNA testing [5]. A summary of recommendations can be seen in Table 1.

\section{Treatment of premutation disorders}

Currently, there are no personalized treatments available for ASD, DD, ADHD or epilepsy specifically associated with FXPM. There are ongoing experimental targeted treatments in FXS that will hopefully inform the development of more precise treatments of neurodevelopmental disorders associated with FXPM in the future [1]. For mood and anxiety disorders, selective serotonin reuptake inhibitors and serotonin-norepinephrine reuptake inhibitors are often used effectively [5,89]. Psychotherapy, particularly, cognitive-behavioral and problem-solving therapy are also indicated, focusing on guilt, anxiety and depressive feelings related to carrier status [39]. Albeit rare, agitation or psychosis may develop at later stages of the FXTAS dementia; atypical antipsychotics are preferred over typical agents to minimize exacerbation of parkinsonism [38]. There are specific pharmacological treatments that can improve tremor, such as propranolol and primidone, which are discussed in detail elsewhere [89-91]. Deep brain stimulation has also been demonstrated to be effective for tremor and sometimes ataxia [92]. While anecdotal reports have indicated cognitive benefits with cholinesterase inhibitors or memantine [24,93], a recent controlled trial of memantine did not demonstrate efficacy on measures of tremor severity or selected executive function tests [94]. Support of the spouse or partner of the patient with FXTAS is essential, as depression is common in these caretakers as FXTAS progresses [95].

\section{Conclusion}

FXPM conditions, as described in this review, may present prominently with neurological and psychiatric manifestations across the lifespan. Thus, the spectrum of premutation disorders can be conceptualized as ranging from early disturbance in neurodevelopment to later neurodegenerative phenotypes. Premutation cases may, therefore, present in a variety of clinical contexts,
Table 1. Clinical indications to obtain genetic testing for fragile $\mathrm{X}$-associated disorders.

\begin{tabular}{|c|c|c|}
\hline Patient groups & Obtain testing & Consider testing \\
\hline Children & $\begin{array}{l}\text { DD } \\
\text { ASD } \\
\text { Family history of FXS and } \\
\text { mood/anxiety disorder }\end{array}$ & \\
\hline Women & $\begin{array}{l}\text { POI } \\
\text { Family history of POI and } \\
\text { mood/anxiety disorder }\end{array}$ & $\begin{array}{l}\text { Family history of POI } \\
\text { Fibromyalgia and any other } \\
\text { clinical indicator }\end{array}$ \\
\hline All adults & $\begin{array}{l}\text { DD } \\
\text { ASD } \\
\text { 'MCP sign' on MRI } \\
\text { Family history of FXS, DD or ASD } \\
\text { and mood/anxiety disorder }\end{array}$ & $\begin{array}{l}\text { Dementia and mood/anxiety } \\
\text { disorder } \\
\text { Family history of dementia and } \\
\text { mood/anxiety disorder } \\
\text { Dementia with a movement } \\
\text { disorder }\end{array}$ \\
\hline
\end{tabular}

often resulting in referral to either neurologists or psychiatrists. Children with the premutation are most likely to present with ASD or ADHD in boys and anxiety in girls. Those with ASD generally lack the dysmorphic features and intellectual disability seen in FXS. Adult carriers may present with psychiatric manifestations on the depression and anxiety spectra, often with an onset later in life than is typical in the general population. Finally, these same adult carriers are at increased risk of developing a progressive dementia with tremor, ataxia and parkinsonism often accompanied by depression and anxiety.

It is critical to understand that FXPM conditions are mechanistically and phenomenologically distinct from FXS. While the latter results from a loss of FMR1 mRNA and protein, FXPM results in elevated FMR1 mRNA and normal or slightly reduced protein levels. Multiple lines of evidence suggest that pathology in FXPM conditions results from toxic gain-of-function effects of the elevated mRNA, though a relative reduction of functional FMRP may contribute in some cases. In the broader context of neuropsychiatric illness, FXPM conditions are representative of an evolving class of disorders with both neurologic and psychiatric features. Since the genetic lesion underlying FXPM disorders has been identified, these conditions may act as an illustrative model of neuropsychiatric disease with a strong genetic basis. Currently, standard treatments are recommended for associated mood, anxiety, cognitive and movement disorders. However, increasing recognition of FXPM cases by practicing physicians will facilitate enrollment of research subjects and enable the next generation of advances in our 
understanding of this class of neuropsychiatric disorders.

Future perspective
Disorders on the FXPM spectrum offer a unique
opportunity to link a defined genetic lesion to
structural alterations in the brain that underlie
neurological and psychiatric symptoms. Several
open questions regarding the etiology of FXPM
conditions remain to be answered. While struc-
tural and functional alterations in the brains of
FXPM carriers probably contribute to the risk of
neuropsychiatric phenotypes, it remains unclear
to what extent the underlying process is neurode-
velopmental versus degenerative in nature. Larger
and more complex longitudinal studies of FXPM
carriers would be helpful to elucidate which clinical
manifestations are eventually associated with the
development of a degenerative process. Ultimately,

neuropsychiatric manifestations in FXPM carriers likely result from a complex interplay of developmental, neurodegenerative and environmental factors. In addition, it remains unclear why some carriers develop FXPM disorders, while others display no symptoms whatsoever.

As our understanding of the molecular and cellular mechanisms involved in FXPM pathology advances, it is likely that new therapeutic avenues will emerge. While a toxic mRNA gain-of-function mechanism is thought to explain neurodegeneration in FXTAS, some FXPM carriers also have reduced FMRP potentially leading to milder phenotypes on the fragile X spectrum [5,96]. Evidence exists correlating both increased mRNA expression and reduced FMRP with clinical phenotypes in FXPM carriers [35,41]. However, such studies must be interpreted cautiously given that their use of proxy

\section{EXECUTIVE SUMMARY}

\section{Neurodevelopmental disorders in carriers}

- Autism spectrum disorder is more common in carrier boys, and maybe in carrier girls, compared with related noncarriers or the general population.

- Carrier girls are at high risk for developing anxiety disorders.

- There is mounting evidence that attention-deficit/hyperactivity disorder and seizure disorders may be more common in carriers, especially in those with autism spectrum disorder.

Neuropsychiatric phenotypes in adult carriers without fragile X-associated tremor ataxia syndrome

- Adult carriers are at increased risk to develop mood and anxiety disorders even before developing symptoms of fragile X-associated tremor ataxia syndrome (FXTAS).

- Mood and anxiety disorders in adult carriers are likely to develop later in life than in the general population.

\section{Neuropsychiatric phenotypes in FXTAS}

- FXTAS is a disorder primarily characterized by tremor, ataxia and parkinsonism that is often accompanied by cognitive decline, sometime progressing to a full dementia syndrome.

- $\quad$ FXTAS can be confused with other disorders that have both movement and cognitive symptoms, so screening for other fragile X-associated disorders in the family history can be particularly helpful in making the correct diagnosis.

\section{Clinical indications for genetic testing in carriers}

- Genetic testing should be considered for any individual with a family history of fragile X-associated disorders and clinical phenotype associated with fragile $X$ premutation, such as autism spectrum disorder, premature ovarian insufficiency, late-life mood or anxiety disorders, or new-onset tremor/ataxia.

\section{Treatment of premutation disorders}

- Treatment of both neurodevelopmental and mood and anxiety disorders in carriers is currently symptomatic; no targeted medications are yet available.

- Good responses to selective serotonin and selective norepinephrine reuptake inhibitors for depression and anxiety in carriers have been observed.

- Cognitive-behavioral and problem solving therapy have been reported to be effective in reducing guilt, anxiety and depressive feelings related to carrier status. 
measurements from blood may not accurately reflect levels in the affected brain regions. Work in animal models of FXPM disorders will be critical to understand the molecular genetic processes that lead to neuropsychiatric phenotypes. As we turn to the future, scientific advances in each of the domains described above will probably lead to an increasingly nuanced understanding of the

\section{References}

Papers of special note have been highlighted as:

- of interest

-. of considerable interest

1 Hagerman RJ, Berry-Kravis E, Kaufmann WE et al. Advances in the treatment of fragile $\mathrm{X}$ syndrome. Pediatrics 123(1), 378-390 (2009).

2 Verkerk AJ, Pieretti M, Sutcliffe JS et al. Identification of a gene (FMR-I) containing a CGG repeat coincident with a breakpoint cluster region exhibiting length variation in fragile X syndrome. Cell 65(5), 905-914 (1991).

-. Initial description of association between the FMR1 gene and fragile $\mathrm{X}$ syndrome.

3 Hall D, Tassone F, Klepitskaya O, Leehey M. Fragile X-associated tremor ataxia syndrome in FMR1 gray zone allele carriers. Mov. Disord. 27(2), 296-300 (2012).

4 Liu Y, Winarni TI, Zhang L, Tassone F, Hagerman RJ. Fragile X-associated tremor/ataxia syndrome (FXTAS) in grey zone carriers. Clin. Genet. 84(1), 74-77 (2013).

5 Hagerman R, Hagerman P. Advances in clinical and molecular understanding of the FMR1 premutation and fragile $\mathrm{X}$-associated tremor/ataxia syndrome. Lancet Neurol. 12(8), 786-798 (2013).

-P Provides a bench-to-bedside overview of the current understanding of fragile $\mathrm{X}$ premutation (FXPM) disorders.

6 Bretherick KL, Fluker MR, Robinson WP. $F M R 1$ repeat sizes in the gray zone and high end of the normal range are associated with premature ovarian failure. Hum. Genet. 117(4), 376-382 (2005).

7 Reiss AL, Freund L, Abrams MT, Boehm C, Kazazian H. Neurobehavioral effects of the fragile $\mathrm{X}$ premutation in adult women: a controlled study. Am. J. Hum. Genet. 52(5), 884-894 (1993).

8 Hagerman RJ, Staley LW, O'Conner R et al. Learning-disabled males with a fragile $\mathrm{X}$ CGG expansion in the upper premutation size range. Pediatrics 97(1), 122-126 (1996).

9 Tassone F, Hagerman RJ, Taylor AK et al. Clinical involvement and protein expression

etiology of FXPM spectrum disorders. Such discoveries add to our evolving understanding of the relationship between genetic risk and complex neuropsychiatric phenomenology. Our hope for the future is that such advances will provide the context for earlier detection and increasingly targeted disease modifying therapies for patients with these conditions.

in individuals with the $F M R 1$ premutation. Am. J. Med. Genet. 91(2), 144-152 (2000).

10 spectrum disorders and attention-deficit/ hyperactivity disorder in boys with the fragile X premutation. J. Dev. Behav. Pediatr 27(2 Suppl.), S137-S144 (2006).

11 Chonchaiya W, Au J, Schneider A et al. Increased prevalence of seizures in boys who were probands with the FMR1 premutation and co-morbid autism spectrum disorder. Hum. Genet. 131(4), 581-589 (2012).

12 Aziz M, Stathopulu E, Callias M et al. Clinical features of boys with fragile $\mathrm{X}$ premutations and intermediate alleles. Am. J. Med. Genet. B. Neuropsychiatr. Genet. 121B(1), 119-127 (2003).

13 Cornish K, Kogan C, Turk J et al. The emerging fragile $\mathrm{X}$ premutation phenotype: evidence from the domain of social cognition. Brain Cogn. 57(1), 53-60 (2005).

14 Bailey DB, Raspa M, Olmsted M, Holiday DB. Co-occurring conditions associated with FMR1 gene variations: findings from a national parent survey. Am. J. Med. Genet. A 146A(16), 2060-2069 (2008).

- Large national survey that shed significant light on comorbid conditions associated with FXPM.

15 Clifford S, Dissanayake C, Bui QM, Huggin R, Taylor AK, Loesch DZ. Autism spectrum phenotype in males and females with fragile $\mathrm{X}$ full mutation and premutation. J. Autism Dev. Disord. 37(4), 738-747 (2007).

16 Dorn M, Mazzocco M, Hagerman R. Behavioral and psychiatric disorders in adult male carriers of fragile X. J. Am. Acad. Child Adolesc. Psychiatry 33(2), 256-264 (1994).

17 Basuta K, Narcisa V, Chavez A et al. Clinical phenotypes of a juvenile sibling pair carrying the fragile $\mathrm{X}$ premutation. Am. J. Med. Genet. A 155A(3), 519-525 (2011).

18 Hunter JE, Epstein MP, Tinker SW, Abramowitz A, Sherman SL. The FMR1 premutation and attention-deficit hyperactivity disorder (ADHD): evidence for a complex inheritance. Behav. Genet. 42(3), 415-422 (2012)
19 Van Eeghen AM, Pulsifer MB, Merker VL et al. Understanding relationships between autism, intelligence, and epilepsy: a crossdisorder approach. Dev. Med. Child Neurol. 55(2), 146-153 (2013).

20 Moore CJ, Daly EM, Schmitz N et al. A neuropsychological investigation of male premutation carriers of fragile $\mathrm{X}$ syndrome. Neuropsychologia 42, 1934-1947 (2004).

21 Kraan CM, Hocking DR, Bradshaw JL et al. Neurobehavioural evidence for the involvement of the FMR1 gene in female carriers of fragile X syndrome. Neurosci. Biobehav. Rev. 37(3), 522-547 (2013).

22 Grigsby J, Brega AG, Engle K et al. Cognitive profile of fragile $\mathrm{X}$ premutation carriers with and without fragile X-associated tremor/ ataxia syndrome. Neuropsychology 22(1), 48-60 (2008)

23 Cornish KM, Li L, Kogan CS et al. Agedependent cognitive changes in carriers of the fragile X syndrome. Cortex 44(6), 628-636 (2008).

24 Bourgeois JA, Farzin F, Brunberg JA et al. Dementia with mood symptoms in a fragile $\mathrm{X}$ premutation carrier with the fragile $\mathrm{X}$-associated tremor/ataxia syndrome: clinical intervention with donepezil and venlafaxine. J. Neuropsychiatry Clin. Neurosci. 18(2), 171-177 (2006).

25 Bourgeois JA, Cogswell JB, Hessl D et al. Cognitive, anxiety and mood disorders in the fragile X-associated tremor/ataxia syndrome. Gen. Hosp. Psychiatry 29(4), 349-356 (2007).

26 Hunter JE, Allen EG, Abramowitz A et al. No evidence for a difference in neuropsychological profile among carriers and noncarriers of the FMR1 premutation in adults under the age of 50. Am. J. Hum. Genet. 83, 692-702 (2008).

27 Cornish KM, Kogan CS, Li L, Turk J, Jacquemont S, Hagerman RJ. Lifespan changes in working memory in fragile $\mathrm{X}$ premutation males. Brain Cogn. 69(3), 551-558 (2009).

28 Hunter JE, Sherman S, Grigsby J, Kogan C, Cornish K. Capturing the fragile X premutation phenotypes: a collaborative 
effort across multiple cohorts. Neuropsychology 26, 156-164 (2012).

29 Hunter JE, Allen EG, Abramowitz A et al. Investigation of phenotypes associated with mood and anxiety among male and female fragile X premutation carriers. Behav. Genet. 38, 493-502 (2008).

30 Franke P, Leboyer M, Gänsicke M et al. Genotype-phenotype relationship in female carriers of the premutation and full mutation of FMR-1. Psychiatry Res. 80(2), 113-127 (1998).

31 Bourgeois JA, Seritan AL, Casillas EM et al. Lifetime prevalence of mood and anxiety disorders in fragile $\mathrm{X}$ premutation carriers. J. Clin. Psychiatry 72(2), 175-182 (2011).

32 Roberts JE, Bailey DB, Mankowski J et al. Mood and anxiety disorders in females with the FMR1 premutation. Am. J. Med. Genet. Part B Neuropsychiatr. Genet. 150B(1), 130-139 (2009).

- Among the first large studies to use structured clinical interviews to demonstrate increased risk of psychiatric disorders among carriers.

33 Rodriguez-Revenga L, Madrigal I, Alegret M, Santos M, Milà M. Evidence of depressive symptoms in fragile-X syndrome premutated females. Psychiatr. Genet. 18, 153-155 (2008).

34 Seritan AL, Bourgeois JA, Schneider A, Mu Y, Hagerman R, Nguyen DV. Ages of onset of mood and anxiety disorders in fragile $\mathrm{X}$ premutation carriers. Curr. Psychiatry Rev. 9(1), 65-71 (2013).

35 Hessl D, Tassone F, Loesch DZ et al. Abnormal elevation of FMR1 mRNA is associated with psychological symptoms in individuals with the fragile $\mathrm{X}$ premutation. Am. J. Med. Genet. Part B Neuropsychiatr. Genet. 139B(1), 115-121 (2005).

36 Al-Semaan Y, Malla AK, Lazosky A. Schizoaffective disorder in a fragile-X carrier. Aust. N. Z. J. Psychiatry. 33, 436-440 (1999).

37 Khin NA, Tarleton J, Raghu B, Park SK. Clinical description of an adult male with psychosis who showed FMR1 gene methylation mosaicism. Am. J. Med. Genet. 81, 222-224 (1998).

38 Bourgeois JA, Coffey SM, Rivera SM et al. A review of fragile $\mathrm{X}$ premutation disorders: expanding the psychiatric perspective. J. Clin. Psychiatry 70(6), 852-862 (2009).

-. Thorough review of psychiatric manifestations of FXPM disorders.

39 Seritan AL, Ortigas M, Seritan S, Bourgeois JA, Hagerman RJ. Psychiatric disorders associated with FXTAS. Curr. Psychiatry Rev. 9(1), 59-64 (2013).

40 Hessl D, Rivera S, Koldewyn K et al. Amygdala dysfunction in men with the fragile X premutation. Brain 130(2), 404-416 (2007).

-. Among the first studies to use functional imaging to demonstrate that amygdala dysfunction underlies psychiatric symptoms in FXPM carriers.

41 Hessl D, Wang JM, Schneider A et al. Decreased fragile X mental retardation protein expression underlies amygdala dysfunction in carriers of the fragile X premutation. Biol. Psychiatry 70(9), 859-865 (2011).

42 Adams PE, Adams JS, Nguyen DV et al. Psychological symptoms correlate with reduced hippocampal volume in fragile $\mathrm{X}$ premutation carriers. Am. J. Med. Genet. Part B Neuropsychiatr. Genet. 153B, 775-785 (2010).

43 Koldewyn K, Hessl D, Adams J et al. Reduced hippocampal activation during recall is associated with elevated FMRI mRNA and psychiatric symptoms in men with the fragile X premutation. Memory 2, 105-116 (2008).

44 Hashimoto R, Backer KC, Tassone F, Hagerman RJ, Rivera SM. An fMRI study of the prefrontal activity during the performance of a working memory task in premutation carriers of the fragile $\mathrm{X}$ mental retardation 1 gene with and without fragile X-associated tremor/ataxia syndrome (FXTAS). J. Psychiatr. Res. 45(1), 36-43 (2011).

45 Wang JY, Hessl DH, Hagerman RJ, Tassone F, Rivera SM. Age-dependent structural connectivity effects in fragile $\mathrm{X}$ premutation. Arch. Neurol. 69, 482-489 (2012).

46 Hashimoto R, Srivastava S, Tassone F, Hagerman RJ, Rivera SM. Diffusion tensor imaging in male premutation carriers of the fragile X mental retardation gene. Mov. Disord. 26(7), 1329-1336 (2011).

47 Seltzer MM, Barker ET, Greenberg JS, Hong J, Coe C, Almeida D. Differential sensitivity to life stress in $F M R 1$ premutation carrier mothers of children with fragile $\mathrm{X}$ syndrome. Health Psychol. 31(5), 612-622 (2012).

48 Paul R, Pessah IN, Gane L et al. Early onset of neurological symptoms in fragile $\mathrm{X}$ premutation carriers exposed to neurotoxins. Neurotoxicology 31(4), 399-402 (2010).

49 Kogan CS, Turk J, Hagerman RJ, Cornish $\mathrm{KM}$. Impact of the fragile $\mathrm{X}$ mental retardation 1 (FMRI) gene premutation on neuropsychiatric functioning in adult males without fragile $\mathrm{X}$-associated tremor/ataxia syndrome: a controlled study. Am. J. Med.
Genet. Part B Neuropsychiatr. Genet. 147B(6), 859-872 (2008).

50 Hunter JE, Rohr JK, Sherman SL. Co-occurring diagnoses among FMRI premutation allele carriers. Clin. Genet. 77, 374-381 (2010).

51 Coffey SM, Cook K, Tartaglia N et al. Expanded clinical phenotype of women with the FMR1 premutation. Am. J. Med. Genet. Part A 146A(8), 1009-1016 (2008).

52 Sullivan SD, Welt C, Sherman S. FMR1 and the continuum of primary ovarian insufficiency. Semin. Reprod. Med. 29(4), 299-307 (2011).

53 McConkie-Rosell A, Heise EM, Spiridigliozzi GA. Influence of genetic risk information on parental role identity in adolescent girls and young women from families with fragile $\mathrm{X}$ syndrome. J. Genet. Couns. 21(1), 59-71 (2012).

54 Boughton M, Halliday L. A challenge to the menopause stereotype: young Australian women's reflections of 'being diagnosed' as menopausal. Health Soc. Care Community 16(6), 565-572 (2008).

55 Leehey MA, Hagerman PJ. Fragile X-associated tremor/ataxia syndrome. Handb. Clin. Neurol. 103, 373-386 (2012).

56 Au J, Akins R, Berkowitz-Sutherland L et al. Prevalence and risk of migraine headaches in adult fragile X premutation carriers. Clin. Genet. doi:10.1111/cge.12109 (2013) (Epub ahead of print).

57 Martorell L, Tondo M, Garcia-Fructuoso F et al. Screening for the presence of FMRI premutation alleles in a Spanish population with fibromyalgia. Clin. Rheumatol. 31(11), 1611-1615 (2012).

58 Summers S, Cogswell J, Goodrich J et al. Prevalence of restless legs syndrome and sleep quality in carriers of the fragile $\mathrm{X}$ premutation. Clin. Genet. doi:10.1111/ cge.12249 (2013) (Epub ahead of print).

59 Jacquemont S, Hagerman RJ, Leehey MA et al. Penetrance of the fragile $\mathrm{X}$-associated tremor/ataxia syndrome in a premutation carrier population. JAMA 291(4), 460-469 (2004).

- Thorough description of fragile $\mathrm{X}$-associated tremor/ataxia syndrome and prevalence in the California fragile $\mathrm{X}$ population.

60 Hagerman RJ, Leavitt BR, Farzin F et al. Fragile-X-associated tremor/ataxia syndrome (FXTAS) in females with the FMR1 premutation. Am. J. Hum. Genet. 74(5), 1051-1056 (2004).

61 Rodriguez-Revenga L, Madrigal I, Pagonabarraga J et al. Penetrance of FMRI 
premutation associated pathologies in fragile X syndrome families. Eur. J. Hum. Genet. 17(10), 1359-1362 (2009).

62 Jacquemont S, Hagerman RJ, Leehey M et al. Fragile $\mathrm{X}$ premutation tremor/ataxia syndrome: molecular, clinical, and neuroimaging correlates. Am. J. Hum. Genet. 72(4), 869-878 (2003).

63 Sévin M, Kutalik Z, Bergman S et al. Penetrance of marked cognitive impairment in older male carriers of the FMR1 gene premutation. J. Med. Genet. 46(12), 818-824 (2009).

64 Kraan CM, Hocking DR, Georgiou-Karistianis $\mathrm{N}$ et al. Cognitive-motor interference during postural control indicates at-risk cerebellar profiles in females with the $F M R 1$ premutation. Behav. Brain Res. 253, 329-336 (2013).

65 Seritan AL, Nguyen DV, Farias ST et al. Dementia in fragile X-associated tremor/ ataxia syndrome (FXTAS): comparison with Alzheimer's disease. Am. J. Med. Genet. Part B Neuropsychiatr. Genet. 147B(7), 1138-1144 (2008).

66 Tassone F, Greco CM, Hunsaker MR et al. Neuropathological, clinical and molecular pathology in female fragile X premutation carriers with and without FXTAS. Genes Brain Behav. 11(5), 577-585 (2012).

67 Al-Hinti JT, Nagan N, Harik SI. Fragile X premutation in a woman with cognitive impairment, tremor, and history of premature ovarian failure. Alzheimer Dis. Assoc. Disord. 21(3), 262-264 (2007).

68 Yachnis AT, Roth HL, Heilman KM. Fragile $\mathrm{X}$ dementia parkinsonism syndrome (FXDPS). Cogn. Behav. Neurol. 23(1), 39-43 (2010).

69 Karmon Y, Gadoth N. Fragile X associated tremor/ataxia syndrome (FXTAS) with dementia in a female harbouring FMRI premutation. J. Neurol. Neurosurg. Psychiatry 79(6), 738-739 (2008).

70 Bacalman S, Farzin F, Bourgeois JA et al. Psychiatric phenotype of the fragile $\mathrm{X}$-associated tremor/ataxia syndrome (FXTAS) in males: newly described frontosubcortical dementia. J. Clin. Psychiatry 67, 87-94 (2006).

- Initial description of dementia syndrome in fragile $\mathrm{X}$-associated tremor/ataxia syndrome.

71 Seritan A, Cogswell J, Grigsby J. Cognitive dysfunction in FMR1 premutation carriers. Curr. Psychiatry Rev. 9(1), 78-84 (2013).
72 Kamm C, Healy DG, Quinn NP et al. The fragile $\mathrm{X}$ tremor ataxia syndrome in the differential diagnosis of multiple system atrophy: data from the EMSA Study Group. Brain 128(Pt 8), 1855-1860 (2005).

73 Kurz MW, Schlitter AM, Klenk Y et al. FMR1 alleles in Parkinson's disease: relation to cognitive decline and hallucinations, a longitudinal study. J. Geriatr. Psychiatry Neurol. 20(2), 89-92 (2007).

74 Adams SA, Steenblock KJ, Thibodeau SN, Lindor NM. Premutations in the FMR1 gene are uncommon in men undergoing genetic testing for spinocerebellar ataxia. J. Neurogenet. 22(1), 77-92 (2008).

75 Hashimoto R, Javan AK, Tassone F, Hagerman RJ, Rivera SM. A voxel-based morphometry study of grey matter loss in fragile X-associated tremor/ataxia syndrome. Brain 134(3), 863-878 (2011).

76 Brunberg J, Jacquemont $S$, Hagerman RJ et al. Fragile $\mathrm{X}$ premutation carriers: characteristic MR imaging findings of adult male patients with progressive cerebellar and cognitive dysfunction. AJNR Am. J. Neuroradiol. 23(10), 1757-1766 (2002).

77 Adams JS, Adams PE, Nguyen D et al. Volumetric brain changes in females with fragile X-associated tremor/ataxia syndrome (FXTAS). Neurology 69(9), 851-859 (2007).

78 Rosen HJ, Allison SC, Schauer GF, Gorno-Tempini ML, Weiner MW, Miller BL. Neuroanatomical correlates of behavioural disorders in dementia. Brain 128(11) 2612-2625 (2005)

79 Abrams L, Cronister A, Brown WT et al. Newborn, carrier, and early childhood screening recommendations for fragile $\mathrm{X}$. Pediatrics 130(6), 1126-1135 (2012).

80 Johnson CP, Myers SM. Identification and evaluation of children with autism spectrum disorders. Pediatrics 120(5), 1183-1215 (2007).

81 Gleicher N, Weghofer A, Lee IH, Barad DH Association of FMR1 genotypes with in vitro fertilization (IVF) outcomes based on ethnicity/race. PLoS ONE 6(4), e18781 (2011).

82 Rafique S, Sterling EW, Nelson LM. A new approach to primary ovarian insufficiency. Obstet. Gynecol. Clin. North Am. 39(4), 567-586 (2012).

83 Wittenberger MD, Hagerman RJ, Sherman SL et al. The FMR1 premutation and reproduction. Fertil. Steril. 87(3), 456-465 (2007).
84 Silva F, Rodriguez-Revenga L, Madrigal I, Alvarez-Mora MI, Oliva R, Milà M. High apolipoprotein E4 allele frequency in FXTAS patients. Genet. Med. 15(8), 639-642 (2013).

85 Rodriguez-Revenga L, Madrigal I, BlanchRubió $\mathrm{J}$ et al. Screening for the presence of FMR1 premutation alleles in women with fibromyalgia. Gene 512(2), 305-308 (2013).

86 Apartis E, Blancher A, Meissner WG et al. FXTAS: new insights and the need for revised diagnostic criteria. Neurology 79(18), 1898-1907 (2012).

87 Mascalchi M, Vella A, Ceravolo R. Movement disorders: role of imaging in diagnosis. J. Magn Reson. Imaging 35(2), 239-256 (2012).

88 Reiner P, Taifas I, Massiou H, Jouvent E. Pure psychiatric presentation of fragile $\mathrm{X}$-associated tremor/ataxia syndrome. Eur. J. Neurol. 20(9), e113-e114 (2013)

89 Hagerman RJ, Hall DA, Coffey S et al. Treatment of fragile $\mathrm{X}$-associated tremor ataxia syndrome (FXTAS) and related neurological problems. Clin. Interv. Aging 3(2), 251-262 (2008).

90 Leehey MA. Fragile X-associated tremor/ ataxia syndrome: clinical phenotype, diagnosis, and treatment. J. Investig. Med. 57(8), 830-836 (2009).

91 Hall DA, Berry-Kravis E, Hagerman RJ, Hagerman PJ, Rice CD, Leehey MA. Symptomatic treatment in the fragile $\mathrm{X}$-associated tremor/ataxia syndrome. Mov. Disord. 21(10), 1741-1744 (2006).

92 Hagerman RJ, Pak JS, Ortigas $M$ et al. Case series: deep brain stimulation in patients with FXTAS. Brain Disord. Ther. 1(2), 1-6 (2013).

93 Ortigas MC, Bourgeois JA, Schneider A et al. Improving fragile $\mathrm{X}$-associated tremor/ataxia syndrome symptoms with memantine and venlafaxine. J. Clin. Psychopharmacol. 30(5), 642-644 (2010).

94 Seritan AL, Nguyen DV, Mu Y et al. Memantine for fragile X-associated tremor/ ataxia syndrome: a randomized, double-blind, placebo-controlled trial. J. Clin. Psychiatry doi:10.4088/JCP.13m08546 (2013) (Epub ahead of print).

95 Iosif AM, Sciolla AF, Brahmbhatt K, Seritan AL. Caregiver burden in fragile $\mathrm{X}$ families. Curr. Psychiatry Rev. 9(1), 85-91 (2013).

96 Hagerman P. Fragile X-associated tremor/ ataxia syndrome (FXTAS): pathology and mechanisms. Acta Neuropathol. 126(1), 1-19 (2013). 


\section{Medscape}

To obtain credit, you should first read the journal article. After reading the article, you should be able to answer the following, related, multiple-choice questions. To complete the questions (with a minimum $70 \%$ passing score) and earn continuing medical education (CME) credit, please go to www.medscape.org/journal/fnl. Credit cannot be obtained for tests completed on paper, although you may use the worksheet below to keep a record of your answers. You must be a registered user on Medscape.org. If you are not registered on Medscape.org, please click on the New Users: Free Registration link on the left hand side of the website to register. Only one answer is correct for each question. Once you successfully answer all post-test questions you will be able to view and/or print your certificate. For questions regarding the content of this activity, contact the accredited provider,

\section{Towards an understanding of neuropsychiatric}

CME@medscape.net. For technical assistance, contact CME@webmd.net. American Medical Association's Physician's Recognition Award (AMA PRA) credits are accepted in the US as evidence of participation in CME activities. For further information on this award, please refer to http://www.ama-assn.org/ama/pub/ category/2922.html. The AMA has determined that physicians not licensed in the US who participate in this CME activity are eligible for AMA PRA Category 1 Credits $^{\mathrm{TM}}$. Through agreements that the AMA has made with agencies in some countries, AMA PRA credit may be acceptable as evidence of participation in CME activities. If you are not licensed in the US, please complete the questions online, print the AMA PRA CME credit certificate and present it to your national medical association for review.

\section{Activity evaluation: where 1 is strongly disagree and 5 is strongly agree.}

The activity supported the learning objectives.

The material was organized clearly for learning to occur.

The content learned from this activity will impact my practice.

The activity was presented objectively and free of commercial bias.

1. Your patients are 6-year-old male and 8-year-old female siblings with a family history positive for fragile X syndrome (FXS). According to the review by Dr. Besterman and colleagues, which of the following statements about children who are fragile $X$ premutation carriers is correct?
A Girls with the fragile $X$ premutation are most likely to present with autism spectrum disorder (ASD) or attention-deficit/hyperactivity disorder (ADHD)
B Boys with the fragile $X$ premutation are most likely to present with severe anxiety
C Evidence suggests that ADHD and seizure disorders may be more common in carriers, especially in those with ASD
D Carriers with ASD have the dysmorphic features and intellectual disability seen in FXS

2. According to the review by Dr. Besterman and colleagues, which of the following statements about neuropsychiatric manifestations in adult carriers without fragile $\mathrm{X}$-associated tremor ataxia syndrome (FXTAS) is correct?

A Even before experiencing symptoms of FXTAS, adult carriers are at increased risk for the development of mood and anxiety disorders

B Compared with the general population, adult carriers are likely to experience mood and anxiety disorders earlier in life

C Effective targeted medications are currently available to treat mood and anxiety disorders in carriers

D Cognitive-behavioral and problem-solving therapy play no role in treatment of adult carriers 
3. According to the review by Dr. Besterman and colleagues, which of the following statements about neuropsychiatric and other manifestations in patients with FXTAS would most likely be correct?
A Onset is usually in the third decade
B Because FXTAS may resemble other disorders affecting both movement and cognition, screening for FXD in the family history can help make the correct diagnosis
$\square$ C The typical presentation includes hallucinations
$\square$ D Genetic testing plays no role in diagnosis 